\title{
The future of East Asia: concept, method and perspective - EU as mirror
}

Shuifa Han

\author{
Correspondence: hansf@pku.edu.cn \\ Department of Philosophy/Institute \\ of Foreign Philosophy, Peking \\ University, Beijing 100871, The \\ People's Republic of China
}

\begin{abstract}
Background: The solidarity of East Asia, or its possible integration, and even the establishment of a union in the future, could not place hope on just spontaneous generation and development of the situation, but should rely on the selfconsciousness and autonomous efforts of the people and politicians in East Asian countries. EU and other various organizations within the East Asia region, not only provide rich experience, but also offer a variety of possible ways and means for the solidarity of the East Asian countries.

Methods: Under the principles of human rights and rule of law, as well as on the basis of equality and consultation, the significance of East Asian integration consists in facing the history, historical ties and cultural heritage fully and independently, in addition to the assumption of the present and future needs, as well as the responsibilities and obligations which have to be taken in joint effort.
\end{abstract}

Results and discussion: East Asian Community, if it is possible, would become one of the main civilization circles of the world, and constitute the core of the modern world system together with the EU, the US and possibly other systems or communities of countries, meanwhile forming a civilization region with special characteristics of culture. Therefore, it bears responsibility for creative development of multi-civilization for human.

Conclusions: Viewing from the cooperation, transition and prospects of East Asia, the political and ideological differences between the East Asian countries and obstacles caused by them are easy to have change, while the social behaviors and ideational structures infiltrating in people's daily lifestyles and attitudes plays a decisive role. Therefore under the premise of reaching the consensus to the maximum extent, maintaining the particularity of societies and cultures of different countries is the key point for future development of East Asia.

Keywords: East Asia, Consensus, Community, EU, Mirror

\section{Concept of "East Asia": History and modern times}

\section{Relationship of East Asian people and general relationship of human beings}

When probing into the relationship of East Asia, we definitely need to take the EU as the template for comparison and contrast, and we also need to understand the inner relationship and significance of the EU from the relationship between the East Asian countries; nevertheless, the point to emphasize here is that such relationship, above all, is the general relationship of human beings. When studied from different disciplines and the different perspectives of specific disciplines, human relationships would present different significances and generate different themes; however, the general

(c) 2016 Han. Open Access This article is distributed under the terms of the Creative Commons Attribution 4.0 International License (http://creativecommons.org/licenses/by/4.0/), which permits unrestricted use, distribution, and reproduction in any medium, provided you give appropriate credit to the original author(s) and the source, provide a link to the Creative Commons license, and indicate if changes were made. 
relationship of human beings is always a basic premise and fundamental background regardless of disciplines or perspectives. This is the precondition that why the relationship between the East Asian countries could be compared with that of the EU, and that the experience of the EU could be used for reference for the relationship between the East Asian countries. In addition to various common natures of human beings, the said precondition naturally contains the common positive values of modern humans, such as human rights, democracy and rule of law, as well as interests, benefits and other reasonable tendency of human beings. It also involves in the general means for dealing with international relations, such as negotiation, consultation, wrestling, competition, international law, and even regulation, sanction, threat of force, intervention, and war. Hence, this general human relationship combines with the specific history, reality, social structure, ideational structure and even lifestyle of East Asia, which contributes to the peculiarity of the relationship between the East Asian countries. The said peculiarity can be studied in the following three aspects.

Firstly, as for the common values of human beings, different countries have different ways of understanding, different implementation forms and different time durations for implementation, which lead to the special realization form of the common values. Superficially, the basic values between the East Asian countries and their basic political systems are quite different, but their coexistence and cooperation are unavoidable. This results in the reality of today's East Asia. Because of this, many East Asian people consider the general human relationship as the specific and particular relationship between different countries, races and political systems. Such an insight tends to make people have a one-sided view and get into the trouble of reality, so that they can't catch sight of the multiple possibilities of development, especially the positive possibilities. In fact, most people of the East Asian countries increasingly tend to be common with regard to the understanding and acceptance of the basic values and concepts of human beings (this is obviously a trend that can be verified except North Korea). Therefore, the key to understand the particularity rests with in which perspective and level to investigate the basic concepts? Official ideology and mainstream values of the public coexist as two different concepts. Although they might be compatible with each other, they always differ from each other. Indeed, the basic values differ in different countries due to this limitation.

Secondly, the history of East Asia, particularly its modern history of colonization and aggression, results in significant change of social development direction, setback of modernization, complex realistic situation, and indelible historical memory in the East Asian countries, forming multiple practical obstacles in respects of politics, ideology, nation, economy, society and even taste. It deters people from mastering and realizing common benefits by understanding, reaching and implementing common values. Because of these special relations, reality and history are memorized in the intellect of common people (or in the common sense of people), which seems closer to people's daily concern and superficial emotion towards benefits, hence it is more likely to be manipulated by politicians and certain interest groups for their realistic political benefits and other purposes.

Thirdly, people's value consensus is always reached by various different ways and means, while the common values are implemented via different systems and measures. Meanwhile, the particularity of the ways and means, however, is not express in advance; it is realized through people's practical social, economic, and political activities, as well as 
through the competition and contest between various political and social forces, featuring unpredictability due to its development in different directions under the influence of political forces and external situations. While in modern society, implementation of such values is not merely the work of one certain country or people-abstractly, it is the common cause of mankind; to be specific, implementation of the values rests upon international cooperation.

Without a doubt, particularity in the above three aspects suggests us with the complexity of the actual relationship. It is just this kind of complexity and probability that requires us to analyze various relations in a prudent manner, and to find out the mainstream or decisive factors and the conditions and spaces for them to come into play. This kind of results will undoubtedly help people make reasonable decisions and take corresponding measures in their practical political judgment.

\section{Commonality and difference}

"East Asia" belongs to a contemporary concept. The "East Asia" mentioned herein mainly refers to China, Japan, Korea, North Korea and Mongolia. Some scholars also call this region "Northeast Asia". However, in modern idiomatic usage, "Northeast Asia" also contains part area of Russia distributed in Asia, yet the discussion herein does not contain this area. Moreover, "East Asia" mainly refers to China, Japan, Korea and 11 Southeast Asian countries ${ }^{1}$ in some research literatures, but the regional boundary of the "East Asia" in this usage is fuzzy. However, the concept of the "East Asia" in this paper both specifies the specific region and narrates it as well. It is closely related due to the profound and long history-although its current situation makes many people of today deliberately evade its actual relationship in the history.

As a neutral geographic concept, "East Asia", superficially, indicates some certain commonality. Nevertheless, when we probe into the specific circumstances of different countries in this region, or further get to know the situations of different people in this region, we will find that the commonality in this concept is far greater than the difference therein. As a matter of fact, people in China, Japan Korea and other countries seldom use "East Asia" in their daily life to refer to the area they live, let alone to use it to refer to their own races and other races.

Some survey data show that the favorable impression between the East Asian countries is much inferior to that of the people of the European and North American countries towards the people of the East Asian countries. For example, Japanese hate Chinese in a degree much higher than American and British hate Chinese. ${ }^{2}$ In this way, "East Asia" turns out to be a pure geographic position. Moreover, Japan's modernization aims at "departure from Asia for Europe" (Japan belongs to the West rather than the East even if in the world politics map today), hence when we talk about the future of East Asia with a view to its commonality, we have to face the negative aspect and meaning of this concept and thus get embarrassed.

However, to smoothen discussion and clarify the problem, facing up to this awkwardness and dilemma is an inevitable step which comes first. It is also necessary to understand the complexity of the problem. One task of this paper is to discover commonality factors from the vast difference of reality and even from the hostility between the 
people of different countries. The future of East Asia will, in a positive direction, be based on this realistic and possible commonality.

The existing categories and fields in modern academics provide us with many readymade pointcuts and approaches for analyzing the commonality. For instance, time division of past, now and future from the perspective of history; the fields like politics, economy, society, nation, language, and custom; region, cultural transmission, historical grievances and other relations. We may have many contradictory conclusions upon investigation respectively on these fields. According to the current situation, the close ties and exchanges between the East Asian countries and people, especially high-level economic dependence and frequent personnel exchanges, still run in a contrary direction with the ratio of likes and dislikes obtained from several investigations. How to explain this contradictory phenomenon? Different viewpoints, methods, visions and attitudes will come up with different conclusions.

Although some part of the inherited common cultures of East Asia still retains today, such as Confucianism, Buddhism, Chinese character, traditional festival system, and daily lifestyle, the situations differ in different countries. In Japan, Chinese character is still a practical tool (yet is increasingly weakened), while it has become a historical memory or a tool for tracing historical memories in Korea and Vietnam. However, we need to carefully investigate and study whether these civilization factors exist in reality or history, or only exist in historical memories. A number of countries take Confucianism as the basic concept, believe in Marxism-Leninism, or almost become Christian countries, so that they all commit themselves to the ideology of the West.

As for the commonality ever existed in history or even that in respect of basic concepts and systems, when they are exerted in people's specific social behaviors and social and political systems, they will turn up with ever-changing differences, still less different countries and races originally had their own concepts, religious believes, and customs, which will localize the transplanted thoughts even if accepted as basic concepts. When people seek cooperation, common interests and peace nowadays, the past or inherited commonality will play an active role and even play a dominant role in a particular way; but when people are entangled in conflicts and rivalries, the difference between different countries or races will play a dominant way. Furthermore, when two or several countries or races enjoy the "honeymoon" of cooperation or show kindness to each other for various reasons, the commonality will be amplified; when they are otherwise entangled in conflicts and rivalries, the difference will be amplified. The relationship between countries is similar to that between people, so that is should be well and truly understood from the perspective of human nature. In doing so is helpful for us to comprehend the changes of commonality and difference, in a way to understand the realistic relationship between the East Asian countries or people.

One particularly important condition should be considered when discussing the commonality and difference of the East Asian countries: in the modernization of the world today, the relationship between the East Asian countries or people is under the great influence of the West-the relationship between western countries to be exact; it is also restricted by the world system. As Japan and Korea share common political values with North America and European countries, the people of these two countries maintain a closer affinity with western people. With the enhancement and predominance of the independent and autonomous consciousness, the East Asian countries or people lay 
stress on their own autonomy and self-esteem, and therefore, think about their difference with the western countries and people, so that their uniqueness, independence, and autonomy will become prominent problems; but when they face the everlasting complex conflicts, especially ideological conflicts and continually pestering historical grievances, some of them would rather seek greater commonality from the western countries and people, while their sense of identity will easily jump out of the East Asia region and seek another definition for their own autonomy. Therefore, the East Asian countries and people are respectively affiliated to different political and geographic locations in respect of this point; or from another perspective, they have the possibility and condition to choose the sense of identity of other regions in the world today.

Market economy and free trade, however, recover the natural ties between the East Asian countries or people to a large extent. The economic ties between the East Asian countries become more and more close, which make their sense of identity in politics and ideology become more and more close and make their historical grievances fade away. The close economic ties, in particular, bring in frequent personnel exchanges, thus forming a new type of mutual influence-the leavening influence of culture, especially lifestyle (e.g., "Japanese wave", "Korean wave"), and even religion. This seems a repetition of some formation process of historical commonality, yet in an opposite direction and directly by an open and folk way. People usually neglect this mutual influence and even the melting within a certain range (for instance, the ever-increasing transnational marriage of people, especially between Chinese and Japanese and Korean), while focus on the conflict events, just like the fixed tendency of modern media and the results caused thereby; but rational thinking and effective theoretical research cannot neglect this tendency and phenomenon, instead, have to show much concern.

The aforesaid commonality and difference do exist and behave in a much more definite and vivid way than in theory, no matter in terms of conflict or melting. Superficially, what people see are always the contradictory phenomena, such as the increasing deteriorated feeling antithesis and the increasing ever-increasing transnational marriage between Chinese and Japanese as well as the increasing number of Chinese students studying in Japan. When we discuss the future of East Asia, the crucial standpoint consists in how to face, analyze and study the causality of various empirical phenomena and the mainstreams in all trends. Another interesting point to take note of concerns insights and methods: on the one hand, people's emotions, usually the most specific and realistic expression of various differences, can amplify various difference and directly result in large-scale conflicts and hostilities; on the other hand, people's practical considerations and behaviors, precisely, form the most important and realistic power surpassing these differences. Economic behavior or personnel exchange and even immigration intensely break through the limitation of these differences, forming some new commonality through establishing some new ties which are small but complete.

\section{History and historical memories}

Regardless of theoretical explanation, people's actual behaviors or even deliberate publicity, historical events and people's historical memories, as a basic yet underlying background, always act as an important and active factor poised for action in the relationship between the East Asian countries or people today. These historical events 
and memories won't automatically come into play, but they are prone to be motivated by the realistic conflicts between different East Asian countries and people. In the meantime, politicians and certain interest groups often manipulate these historical events and memories for their own benefits and purposes. Comparing with close economic dependence and personnel exchanges, and even the influence of leavening, daily and specific lifestyles, some factors of the historical events and memories like invasion, colonization and slaughter, with their concise expressions and concepts, directly resort to people's emotions, thus being the factors more easily to be launched and manipulated to bring up rivalries and enlarge differences.

The modernization of Japan after Meiji Restoration motivates its originally latent arrogant concepts and desires, such as self-centered, impulse of expansion, and upstart mentality and imposing manner caused by its rapid rise and despising other East Asian countries and people. Exposed to the education, demonstration, encouragement and cooperation of Western imperialism and racialism behaviors and theories, Japan invaded and colonized the whole East Asia and then the whole Asia. The leadership and elites of Japan, of course, made up many reasons for such invasion and colonization, including the grandiose excuses of Asian Independence and East Asian Association Campaign. The self-deception of such excuses was self-evident in front of the direct occupation, slaughter and looting; moreover, there were the disregarded desires, plans and goals for conquering China and Asia that were then expressed in public by the Japanese elites. Japan's invasion caused overwhelming disastrous consequences to East Asia and even the whole Asia. It interrupted the ongoing modernization process of East Asia, especially that of China, including the process moving towards constitutionalism. It further interrupted the modernization process of other Asian countries. Thus, Japan destroyed the generally formed international order and balance of power of East Asia, resulting in more in-depth intervention, interference and colonization of Western imperialism towards East Asia and the whole Asia, and in particular, helping the Soviet Union in expanding its sphere of influence in East Asia and the whole Asia and inducing a lot of disastrous events. Generally speaking, Japan basically played a passive role for the modernization transformation and constitutionalism of the whole East Asia region from the end of the $19^{\text {th }}$ century to the first half of the $20^{\text {th }}$ century. Even to this day, Japan's elites (including intellectuals) still lack of deep introspection; in fact, even the people of the victim countries still lack of full recognition and understanding, only treating the passive influence as the acts of aggression, including slaughter, humiliation, looting and destruction. After joining the US-led Western camp, Japan (including its elites and common people) discarded the external pressure and reason for introspecting and self-criticizing Japan's crime in the past. Furthermore, Japan's democratization and Chinese government's waiver of holding Japan to account over the war (including occupation and compensation) made Japanese government and people exempt from or at least weaken their moral obligations for the aggression and brutal war.

Confined to their own realistic benefits, camp belonging, ideology and field of vision (such as the implementation of Soviet systems in China), other Asian countries also lack of comprehensive and in-depth research and thinking. China, the biggest victim, in particular, retrospects the least. Many Chinese people only treat the grievances and resentment at emotional level and Chinese elites still lack of a macroscopic point of 
view. Moreover, Chinese academia still lacks of comprehensive, overall and in-depth analysis and research. All these make the Chinese society fail to cognize and comprehend, in a comprehensive, objective and reasonable way, the causality, historical consequence and far-reaching influence of the important events in the modern history, let alone to find out the reasonable and correct way out of the historical memory and severe consequence; naturally, Chinese people area hard to get the just cause to snap back from the negative emotions caused by the double historical effect.

Complex situations in politics, societies and emotions are formed on the basis of the historical events and memories between the East Asian countries due to many reasons. Here are some undoubtedly important reasons: 1) realistic political systems of the western countries after the Second World War; 2) ideological conflicts and the opposition of the two camps centered on the "Cold War"; 3) lack of autonomy and relative backwardness of the East Asian countries and region. These factors seriously hinder the countries in East Asia and Asia from establishing and expanding their consensus and trust through mutual cooperation, including the consensus and trust for fact finding and nature judgment over the historical events.

Even till today, Japan's democratization and it's entry of the US-led Western camp cannot exempt it from its war crime in the history and corresponding moral and legal responsibilities, in addition to its destruction in the past; similarly, Germany's postwar democratization cannot exempt Nazi from its crime and war responsibilities, so do its destruction for Europe in the past even if it keeps making contributions for Europe today. Many people still cannot make it clear for this point. In the western world, many people prefer judging historical events from the current affinity, which is one of the important reasons that cause misunderstanding of history.

Another point closely related to this one is that, for many victim countries and people in the history, the historical crimes and responsibilities of Japan cannot be eliminated by its liberalization and democratization. It cannot be judged that no change to Japan is caused by liberalization and democratization. Moreover, it cannot be concluded that the systems and values of liberalization and democratization should be rejected.

\section{Mentality}

Modern international relations focus on economics, politics and laws, while people's mentality ${ }^{3}$ in each country usually influences political and economic decisions in a subtle way, and directly unleashes enormous force at a crucial time, giving rise to the social consequences that usually last for a long time due to instant unleashing. People's mentality, to be exact, the mentality centering on the relationship between countries, maintains stable in a long time though it may considerably fluctuate in a short time; however, short-term fluctuation makes people's attitudes tend to be biased; it also can cause decision-makers to make error judgment along with emotional, short-sighted and wrong decisions, hence resulting in irreversible consequences and changing the relationship between countries under great influence. If this situation sustains, the originally temporary mentality will gradually become enduring. Indeed, this situation tends to exist between the countries lacking of political consensus and common basic concepts, yet in or between the countries and communities with remarkable degree of consensus in values, different people or races in the communities would have mentality 
fluctuations due to interest conflicts-even superficial interest conflicts, differences in language, culture and habit, as well as historical factors-even variation of historical memories, thus leading to separatism or other demands and actions, such as the timehonored independence movement of Quebec, and the rising Scottish separatist movement-whereas the majority people in today's Scotland might have little to do with the Scottish people in the history.

Based on the achievements in economy, society and politics, Japan, Korea and China's Taiwan and Hong Kong areas have taken the lead in setting up self-confidence for the races, societies and individuals of the East Asian people, and have established the basic principles for modern market economy and society of rule of law, setting an example for other East Asian countries and regions. This phenomenon is of enormous psychosocial impact and significance for East Asia and the whole Asia. Nevertheless, this kind of psychosocial significance is multidimensional rather than one-dimensional and rather different effects can be produced in different relations.

In 1924, a speech themed The Great Asianism by Sun Yat-sen in Kobe of Japan pointed out that Japan's rise, abrogation of unequal treaties and victory over Russia had ever aroused the hope of Asian people, that is, to seek for independence by learning from Japan. However, what Japan did to East Asia and the Asian countries made Sun Yat-sen have to directly warn to Japan: "You Japanese nation not only get the despotic culture of Europe and America, but also retain the nature of the kingly culture of Asia. Regarding the future of world culture from now on, will you act as the despotic lackey of the West or the kingly rampart of the East? ${ }^{4}$ This warning is of generality. It is a warning for all countries, which contains positive and negative meanings-warning the despotic Japan, as well as China and other countries which might be exposed to despotism. Japan has effectively followed the double standard then prevalent in the western countries: adopting different standards for its own people and other countries, especially for underdeveloped and weak and small countries. This complex mentality, which existed at the turn of the $19^{\text {th }}$ to the $20^{\text {th }}$ century in East Asia, is a key to understand the relationship between the East Asian countries. Similarly, it is helpful for people to understand the complexity of the mentality of today's East Asian people.

This mentality, of course, is the compound of history, historical memories and realistic conditions. Nowadays in East Asia, people with sound mind have diffident attitudes and judgments for different relations. It is very hard for them to have a general attitude for all things. Supposing the East Asian countries have a better understanding of their mutual relationship, their mentality would become more complex. Such a complexity, actually, also plagues social elites. As for academic research, this may be a treasure-the more complex phenomenon, the more value of research; as for the decisions of behaviors and politics, it is no doubt a great difficulty. Comparing with today, only few talent people in the time when Sun Yat-sen addressed his famous speech had such a complex mentality and corresponding complex thinking from common people to elites.

East Asian people pose quite different attitudes towards their past common culture. The conditions are different yet interlaced with each other. For instance, Japanese government abolished all calendar and holiday systems (once retained through contention by the people in remote rural areas for several decades) obtained from China, while retained some Chinese characters and lifestyles, including but not limited to dietary and dressing modes which tend to decline today. Korea and North Korea 
abolished Chinese characters in the 1950s and 1960s, yet retained the major holiday systems from China; however, the public of Korea tend to treat them valuable till today as the things of their own nation, isolating the original ties with China. Nevertheless, the traditional culture has suffered from the most serious destruction in China. In most cities above county level of China, we can hardly see traditional buildings and streets; according to the administrative division of China, traditional urban layout and buildings in the cities above city or district level, apart from few cities like Beijing with small number of residuals, nearly have totally vanished. Nowadays, traditional holiday systems are recovering in a reluctant way, but the significance is in no way different from putting new wine into old bottles. Here, we are curious about that, now that the relationship of all the countries and people go far gradually with the traditions, how the traditions, historical events and historical memories play their roles with regard to the mentality of the people today? What of the history are mostly concerned by the people according to the relationship between the East Asian countries and people? What events in the history can be capable of touching the motions of the people? These two questions look alike, but in fact, they are quite different from each other. The first question is more important when we get to know the mentality of people and the relationship between the East Asian countries, because it suggests us that the effect of all the historical issues between countries or people ultimately depends on the relationship of reality. The saying of B. Croce (1866-1952) "all history is contemporary history", if used here, is quite appropriate. ${ }^{5}$

At this point, I just can roughly outline the mentality of the people of some East Asian countries, which would likely be controversial.

One point that people should have an in-depth understanding is that the mentality of contemporary Chinese people is the most complex one by comparison with that of all the East Asian countries and even all the countries in the world. The condition is similar in terms of how they treat history. The said mentality generally has two characteristics: 1) the ambivalence about the pride and depression of history and tradition culture, which makes the people have different opinions, though recently, more and more people hold positive attitudes towards history and tradition; 2) the humiliation, selfabasement and disobedience about modern history. Although the mentality of the Chinese people today is quite complex and different, it always tends to be reasonable and rational in general, which is the basic driving force for Chinese society to keep improving and also the social basis for China to make achievements. The development of modern network technologies such as WeChat makes Chinese people have a greater micro space, where their mentality could be presented in a relatively realistic way and we can catch sight of their realistic differences and conflicts.

Japanese people also hold a complex mentality towards history. Different points of view can be expressed in public in a modern liberal democratic society, which does not mean all the opinions can be expressed. However, the mentality of most Japanese people, since Meiji Restoration, has been featured with the superiority formed by Japan's achievements compared with that of the East Asian countries and the corresponding discrimination against the other countries-yet, in the democratic society, it is hardly expressed in public exaggeratively, but it can be reflected in communication behaviors rather than expressed in public places. For example, it can be expressed in social surveys and statistics. Avoiding historical records is a human nature that can be 
forgiven, for no people toss around frequently its crimes and faults, and so it is the public mentality of a nation. People may sympathetically understand that most Japanese people don't want to face up to what their predecessors did in China and other East Asian countries, and that they treat them as intolerable history which insults their current conscience and morality. Nevertheless, Japan's invasion of China is barbarous. Referring to its plans and actions of interference, aggression and partition to China since modern times, as well as the huge damage to modern China, the Japanese government chose an extremely careful wording, only limited to "deep introspection", yet without guilty conscience. After the Chinese government exempted Japan from its war indemnity and other responsibilities, due to China's joining in the Socialist camp, the Japanese government and people got more sufficient political and ideological reasons to avoid the war responsibilities. In the negotiations on the normalization of SinoJapanese diplomatic ties, China's policy makers were deficient in the experience and art meeting the code of conduct of the modern world: on the one hand, China accepted Japan's "deep introspection" - an understated expression-in the "Sino-Japanese Joint Statement", and exempted Japan from its war indemnity and other responsibilities as well; on the other hand, they repeatedly mentioned this part of Japan's history in mutual communications and tried to acquire a psychological advantage by taking this part of history as an argument. As a result, some Japanese people got the cause for gossip against China: now that the Chinese government then accepted that expression in the formal statement, why it now criticizes Japan for not apologizing? The most vital careless omission is that, in 1972 when China and Japan established diplomatic relations, these important decisions were not formed within a large range, and they were not made out of the wishes of the public. Therefore, there was a sizable gap between the governmental behaviors and the public requirements and mentality.

When talking about people's mentality, someone may question why mentality is of so important significance? In fact, significant historical events and major behaviors between countries are directly related to people's mentality; in the period when various social problems, contradictions and conflicts emerge simultaneously, or in the period of turmoil and crisis, mentality is even a main force contributing to the occurrence of great unexpected events. There is no need to mention the relationship between people's mentality in the first three decades of the $20^{\text {th }}$ century in Germany and the political tendency of Germany, so do the function of people's mentality of Germany along with the changes in the relationship with its neighboring countries, and the cognition for this situation of M. K. E. Weber (1864-1920) and his warning of patience upon German people. ${ }^{6}$ What's more, modern democracy and corresponding systems are a shell covering on the mentality of people. The hardness of this shell rests with various factors, but people's mentality is somehow a kind of decisive factor. Even in Europe and America, there always lurks and unconsciously exits people's true mentality; once activated by the trend of the times, it will be embodied in and reflected as some political powers and forces. In 2014, the victory of France's far-right party, National Front, suggests that, the shell of liberal democracy is not hard as people think. Therefore, we need to think about how the shell could be maintained in a reasonable and positive way when we highly appreciate Japan's liberal democratic systems.

Korean people maintain a very complex mentality both for China and Japan. Traditional Chinese culture had ever had great influence on Korean (North Korean) culture, but in 
the history of more than two thousand years, China had even launched wars against and taken control over Korea, treating Korea as its vassal state for a long time. Japan also controlled, invaded and annexed Korea for a long time in modern times. Korea's success in modernization and economy shows the great creativity of Korean people; in particular, its economic takeoff ahead of mainland China, as well as its sound social order and people's positive image in the world, make Korean people have an unique sense of pride by comparison with its past. Another complex mentality of modern Korean people is developed as a result of Korea's subordinate status and suffering from invasion and colonization in the history, and the combination of the past backwardness and today's achievements. This is obvious as their impression for China and Japan is less favorable than European countries. There are several big Korean communities in Beijing and Qingdao, but cannot fundamentally change Korean people's mentality for China. Korean people's mentality for Japan is of the same situation. The ratio of Korean people who think that Japan's apology for its war of aggression is not enough is higher than that of Chinese people. ${ }^{7}$

\section{Europe, EU and China}

\section{Dualism of Europe's image}

Europe and other western countries are always an important force in the modern transition of East Asian and even the whole Asia, even acts as a decisive force in a long period. The discussion about the future of East Asia naturally covers its relationship with Europe and other western countries. This paper focuses on Europe, especially the reference significance and model effects of the EU for East Asia.

Europe and the so-called general West concept at least have a dual meaning in eyes of Chinese people; further study should be made to confirm if this situation also applies in Japan and Korea.

Simply for the purpose of benefits, the UK and other European countries broke through the closed-door China. When they invaded, looted and divided China, they forcibly involved China into the process of modernization and made China enter the West-centric world system. Up to now, this kind of historical fact and memory is still an important background for Chinese people to observe and understand the western world, and also a perspective usually selected and even definitely a method. It is particularly important that the western world has not yet completely abandoned their dual-standard code of conduct so far. This will surely deepen the above historical memory that usually in combination with the historical memory concerning Japan's aggression against China, forming a West concept in political and geological aspects. Even though there is such a background in Japan and Korea, certainly, it is more likely to fade away.

After the Second World War, the establishment and expansion of the EU set up a new and good example in Europe, i.e., the countries after a thousand years of warfare and with hostility against each other reached the cooperation intention and then unified to form a new political community, which brought in the overall progress of Europe in terms of politics, economy and society, and provided the experience and example for cooperation between the countries with complicated history and hostility to each other within the same region.

Sketch Map of EU Member Countries. 


\section{Experience of the EU}

The experience of the EU is of multiple significances for the future development and cooperation of East Asia.

1) The progress of the EU, after the Second World War, started under the preconditions that the UK, the US, France and other countries occupied and completely transformed Germany and that Germany assumed all the moral and material responsibilities of the war. This kind of transformation provided a common foundation for the connections in politics, economy, society and other fields between countries, including the relaxation and easing of the people's opposing and hostile mentality. The precondition for establishing the Coal and Steel Community not just contained the commonality of political systems (i.e. implementation of liberal democratic systems), but also contained the mental tenderness and forgiveness between different people.

2) After the Second World War, although the US naturally became the leader of Western Europe and the whole western world, Europe was still the starting point and birthplace for modern civilization. In the eyes of the Western European people, the US's civilization was no more than their expanded civilization in another region, at most a new territory of the same civilization system. The US people also believed they belonged to the European civilization. Even if just within Europe, the founding countries of the EU actually had high sense of identity for their own civilization. As for this area, there was such an important mentality atmosphere: people of the Western European countries did not believe there were better civilization systems other than their own civilization, and they also did not believe there were more rational or advanced systems other than their own systems, regardless of the systematic differences between different countries. Such consciousness assured their autonomy and self-confidence in their civilization, systems and other fields. The politics, national relations and military affairs of Western Europe were under the control of the US in a quite long period, but this only related to the leadership of politics and military affairs, rather than relating to the relationship between different civilizations and the political system difference between different countries as well.

3) The EU was initiated from those countries that had close ties. The so-called "close" contained complex contents-long-term hostility and conquest, common history, culture and religion, especially economic complementarity. Cooperation in economy was the motive power of Europe.

4) The member countries of the EU, especially its founding countries, always adopted and adhered to a dual standard politics, society, economy and culture among others. They implemented a set of principles and standards within their own countries and communities, while implementing another one within their colonies or the countries adopting different politics, region, culture, economy, etc. No doubt, they carried forward the inherited traditions, yet embracing change and progress in specific content and means. When people consider the experience and example effects of the EU from the standpoint of other than the EU, the function and significance of this factor will be remarkable. The dual standard, on the one hand, is definitely a discrimination against the countries other than the union, but it effectively enhances the cohesion and sense of identity within the EU members. 
Turkey still not has been accepted by the EU yet, serving as an importance reference for observing the existence and strength of the dual standard. Similarly, Croatia and Slovenia, which were split from former Yugoslavia, have joined the EU, while Bosnia and Herzegovina, whose population is mainly Bosniak (i.e. the Muslim of former Yugoslavia) and Serbia, still not be accepted by the EU up to now. ${ }^{8}$

5) Democratic country is a political community appeared in modern times in Europe. The Western European countries and their national boundaries were preliminarily set up in modern and contemporary times by means of trade, religion, revolution and war, etc., generally formed at the end of the Second World War, and finally determined by the end of the $20^{\text {th }}$ century. Comparing with Europe, East Asia, especially China, is an extremely precocious modern country, though its various forms are not yet fully developed comparing with the modern western countries which have surpassed it. Therefore, the boundaries of each country in East Asia were explicit for near one thousand years, which was quite different from the history of Europe. Before the Second World War, rise and decline of the political communities like "country" was a frequent phenomenon, which may probably happen even if till today. After more than two thousand years of rise and fall, the territories and boundaries of the European countries were generally determined. The core countries of the EU, i.e., the major countries of Europe, unconsciously shaped themselves as democratic countries through the last war, thus reaching a coincidence in systems. Such a coincidence, at least in nowadays, is the primary condition to ensure boundary and relationship stability for the European countries, and serves as the basic condition that makes the boundaries less and less important-this point is of great significance of enlightenment for the East Asian countries.

6) The EU has set up common values for all tis member countries, so did the internally consistent basic legal systems and other principles, which lay a foundation for peaceful development. However, this does not suggest there is only cooperation, but no competition between the EU countries. As a matter of fact, the EU countries differ from each other in economy, culture and society among others. They even have tremendous competition in these aspects. Such completion is embodied between the EU member countries, as well as between the various trends of thought and political forces within the EU-the election results of the EU Parliament in 2014 suggest such a reality.

\section{East Asia, Europe and modern international relations}

The basic principles and theories of modern international relations are gradually drawn up by western people according to the long-term relationship evolution between the western countries, though with a centuries-old history, yet mainly serving for the relations between the European and Western countries and always behaving awkwardly when they are used in the relations between the East Asian countries and the European countries. In fact, they are always inadaptable to the relations between the countries in other regions of the world, and in the modern academic field fairly lacks of the theory framework and elaboration means for the history of East Asia and the relations between its nations in the history. The theories on modern international relations may 
apply to the relations between the East Asian countries, but they inevitably involve the historical problems. The conflicts between the East Asian countries are mainly left over by the history, but such problems are beyond the reach of the theories of modern international relations.

Therefore, the future of East Asia, no matter in which direction-is to gradually achieve the integration of politics via the integration of economy and even establish the East Asian Community; to stay as it is or go in exactly the opposite direction, i.e., establishment of different communities with the countries outside of East Asian countries and appearance of different and even opposing communities in East Asia; or to come with the situation of a community coupled with isolated countries-will serve as a process for constructing the new patters and theories of international relations. From this point of view, theoretic research and practical exploration have the same significance.

The ancient East Asia had its own unique community- "tribute system", wherein China held a central position in a long period of time and no other central position appeared even though China lost its own, but there were definitely some other countries which intended to take over the central position. Under this system, all the member countries of East Asia accepted Confucianism and become the core members. From this point of view, Confucian culture is overlapped with the "tribute system", but the "tribute system" is far beyond the circle of Confucian culture. The "tribute system" also suggests a class relationship, so that other countries outside of China still don't like to mention this relationship so far-this can be naturally understood, but it also suggests that such a historical relationship is not totally positive in the eyes of the East Asian people. As a historical memory, it definitely owns the potential for playing an important role, yet it lurks in a compound mentality in the contemporary world, rather than automatically playing its own role.

The EU, or the imaginary North American alliance, along with the communities in other areas, bring in a lot of challenges and problems East Asia now and in the future. For instance, if there is still the affinity or even the basis of affinity between the East Asian countries at the present times? Whether East Asia should stay as it is when other areas in the world undergo regional cooperation and alignment? That is to say, they keep at a distance from each other in the fields like politics, society and mentality, but they depend upon each other in economy and subtly affect each other in culture through folk channels. However, the direction is usually from liberal democratic countries to illiberal democratic countries. According to the development tendency of the modern world, if in the absence of integration, the East Asian countries will finally join in other alliances or communities. In other words, East Asia might become a divided region. Besides, no single country in East Asia can creatively demonstrate its ability of autonomy, and it's hard for them to give their creative influences into play in constructing and improving the present and future world order and system. In this context, all the East Asian countries boast the possibility of becoming part of the western civilization from a long run.

Therefore, alignment of the European countries is not merely the pure renaissance and continuation of the traditional European unity concept and practice, while it is more likely a choice made along with the multi-polarization out of the alignment of today's world-for those participant countries, this is a optimal combination which can 
directly contribute to the positive future development of the EU countries in terms of politics, economy and culture among others; while this kind of future development cannot be achieved by a single country. Apart from other reasons, the EU is becoming a powerful center which will attract more and more countries. The continuation of this situation to this day gives rise to such a fact-or becoming a member of the EU, or becoming an inferior lonely country discriminated and restrained in all aspects. After the Second World War, the core countries of Western Europe finally realized that the war cannot solve the core problems and conflicts between them. Nevertheless, this does not mean they have abandoned using force for other countries outside of alignment. In a period not more than 30 years between the $20^{\text {th }}$ and $21^{\text {st }}$ centuries, they waged several large-scale wars in the world (including in Europe), split several countries and incorporated them into their own alliance. In the foreseeable future, the EU will expand its territory to other places outside of Europe. Supposing this is put into effect, the history will be refreshed rather than coming to an end or becoming a simple repetition.

Another point is also worth mentioning: western civilization is still mighty in modern times; although it features various other uncertainties, the westernization of the whole world is still a powerful trend. Here we have a significant problem that concerns human's future and mode of survival, i.e., whether human civilization should maintain its diversification or move towards simplification. Now, amongst all other regions, only the East Asian Countries are most likely to create a new type of civilization for mankind, for they embrace various historical, potential and realistic conditions, which will make people live in a world of multiple choices and enable them to choose different civilizations, cultures and lifestyles. Of course, people can imagine a prospect that western civilization splits again in different forms and diversifies due to multicenter in the future development, but this is not covered in this study.

\section{Significance for composition of "East Asia"}

In the various doctrines and theories for the formation of the modern world, one point is fairly clear and undeniable: modern countries and their mutual relations are established by people consciously and spontaneously; this feature is more distinct if more close to today. It is of great methodology and practical significance for us to realize this point of view. The opposing point of view is that: all the orders of human society are spontaneously formed and people can't, taken as a whole, design and implement a set of orders for a country or society (let alone the super communities like the EU), because the orders of human society are too complicated. This point of view is pretty convincing under this precondition: as for the construction of all new systems, especially that of political communities, the political entities, such as the overall framework of the political communities of the US and the EU, the federal system and partite political system of the US and the capability mechanism of the EU, are newly established, but this does not hinder the factors and basic structures or the components and local structures of the basic principles therein, let alone the systems drawing existing details-though they are also adjusted in accordance with the basic principles. Hence, the "theory of spontaneous generation of human nature", as a whole, is hardly to find a footing. Therefore, the future of East Asia could not place hope on just spontaneous generation and development of the situation, but should rely on the self-consciousness 
and autonomous efforts of the people and politicians in the East Asian countries. EU and other various organizations within the East Asia region, not only provide rich experience, but also offer a variety of possible ways and means for the solidarity of the East Asian countries. The solidarity of East Asia in the future, or possibly integration and even establishment of alliances, depends on people's active and conscientious construction. The future trend and selection of East Asia, at all events, fundamentally depend on how to select and decide by the core countries of East Asia. As they are still faced with many great difficulties till today and it now seems hardly for them to get out of the trouble: there are still great differences and conflicts in political systems between the core countries; some countries are still at the status of division, including the risk of internal conflicts. Consequently, the following points should be clarified.

1) A bran-new international relationship is essential: the cooperation between or integration of the countries which originally had lots of similar cultures and now have different political systems, beyond doubt, require updated theoretical means and practical methods.

2) The integration or communalization of East Asia should be based on the autonomous requirements of the East Asian people and take such requirements as a driving force. It doesn't serve for pure economic benefits, while is required to get consensus in basic concepts and bear the mission of human civilization. In principle, framework, form and other aspects, it definitely includes something same or similar to the EU (such as the principles of human rights and rule of law, necessary and separate authorities); but in many other aspects, it still has great difference with the EU.

3) The East Asian Community will become the most important civilization circle in the world, constituting major systems of the modern world together with the systems of the EU and the US and other possible systems or communities, and in the meantime, forming a civilization area with distinct features. In addition, it bears the responsibility of creatively developing the diversified civilizations of mankind.

4) The integration of East Asia and establishment of a community between different countries is bound to require significant innovation in the nature and form of each country. Such integration and communalization will bring about a certain new framework or structure. One point should be noted that innovation should be a development process towards such a structure, as well as a gradual formation process of new structures via exploration and adjustment. The basic motivation for the integration and communalization of East Asia is bound to be from economy ${ }^{9}$, while the motivation of economic cooperation-including people's exchanges-when entering a certain phase, will inevitably lead to great reforms in political systems and adjustment of people's mentality. The conflicts between political systems and mental contradictions of people will inevitably hinder the effective running of economic motive force. People cannot imagine the exact order of the reforms and adjustment, but it is necessary for them to reach a consensus about the most basic concepts, principles and historical problems. However, such consistency is just the periodical result of the whole integration process, neither its precondition nor its final target. 
5) The significance for the integration of East Asia and its autonomy rests with: in the principles of human rights and rule of law and on the basis of equality and consultation between different countries, to fully and independently face up with the history, historical ties and cultural heritage for the common responsibilities and obligations that need to and should be undertaken now and in the future.

Nevertheless, the cooperation between the East Asian countries still contains competition in economy, culture and other spiritual fields-this is an important way for stimulating the creativity of the East Asian people, just like the situation in other places in the world.

6) Such integration or communalization is not to eliminate the characteristics of the civilizations of each country, but to maximally guarantee the characteristics. Compared to the European civilization, traditional civilizations of East Asia have greater consistency, but they had tremendous difference in concepts, systems, implements, buildings, aesthetics and other aspects. In modern times, these characteristics become more distinct because each East Asian country develops in its unique ways, especially due to the influence of contacts with different international systems. In the development process of the world, only the regional community that shares certain cultural characteristics and maintains a certain scale can ensure the unique development of its civilizations with historical continuity. The huge impact suffered by Germany today in academic sector and its trend of marginalization is the best proof.

Someone may question: now that we need to maintain the civilizations characteristics of each country, why we need integration and communalization? The answer can be varied. Only one point is emphasized here: the modern world is in an era of common alignment. Indeed, human society had alliances since the ancient times, and common alignment becomes a major characteristic of today's international relationship and world order. Modern alignment, different from that of the past, tends to communalization; its basic principles are the uniform three public-interest principles of Kant. ${ }^{10}$ "Nonalignment" is an outdated practice. Regional combinations and organizations in a larger range make the whole world left of few nonaligned countries. Nonalignment was probably a means for weak countries to protect themselves, but now, the countries upholding "isolationism", on the contrary, lack of protection-may either be smartly independent or sadly declined. Therefore, alignment of the East Asian countries is necessary for the majority of countries, and the key is who to align with? And how?

Since integration or communalization resorts to composition, let us talk about the reasons for composing or not composing integration or communalization and find out if the reasons are sufficient for composition or not.

First of all, the positive reasons: (1) naturally and primarily, the bordering in geography, without of which integration or communalization is just a topic hard to speak of; (2) the close relationship in history and the ever common civilizations, or the commonality of civilizations; (3) the existing certain common civilization legacies, some similar social structures and concept structures; (4) the close economic ties between different countries and the trend of integration; (5) the ever-increasing exchanges between people of different countries; (6) the close correlation of the East Asian environmental conditions; (7) the trend for enhancement of regional combinations in 
politics, economy, and society in the world. These seven points are sound reasons, wherein the $4^{\text {th }}$ and $5^{\text {th }}$ points are natural trends which will become intense if without human intervention.

Secondly, the negative reasons: (1) the differences of political system and ideology, especially the peculiarity of China's political system and ideology; (2) the historical problems-they are big obstacles as far as mentality is concerned, as historical memories are hard to vanish; (3) the distrust and hatred between people; (4) the differences in country scale; (5) the incomplete unification between China and Korea (North Korea); (6) China or Japan respectively maintains a better relationship with the Southeast Asian countries. In these six points, the $1^{\text {st }}$ one is the foremost obstacle that is most difficult to overcome and regarded as a dangerous road. The $2^{\text {nd }}$ one lasts for a longer period and is more difficult to overcome, but people's emotions can be calmed downed via political and social adjustments. The $3^{\text {rd }}$ one, though suggesting the important manner, collides with the close exchanges between people. What is the mainstream? The $4^{\text {th }}$ one is a situation that the EU does not encounter yet (though the EU contains countries of different sizes, but its core countries are similar in size); it is easy to rise up and become a big obstacle. As for the $5^{\text {th }}$ one, people may even consider that the integration and communalization of East Asia serves as a sound means for the solution of national division.

Undoubtedly, the analysis here concerning the positive and negative reasons is just a preliminary and brief discussion. Such theoretical analysis is only to point out the contrast between positive and negative forces for the integration and communalization of East Asia. Further theoretical study should be made to analyze the possible and changeable models of various factors and reasons. In reality, however, the growth and decline of these factors depends both on the activities of people and the judgment and decisions of politicians. Here, it is unable to thoughtfully figure out how various factors evolve in the realistic national and international politics, and in which direction they evolve; similarly, it is unable to thoughtfully figure out, in a long run, what factors play the dominating and decisive roles. To be specific, it is unable to figure out if the positive reasons prevail over the negative ones. To carry out corresponding predictions, comprehensive and in-depth research should be made.

Two viewpoints in The Clash of Civilizations and the Remaking of World Order of S. P. Huntington (1927-2008) can well help us understand and analyze the composition of the integration and communalization of East Asia. The first viewpoint "core countries" was mentioned when he discussed the structure of civilization. ${ }^{11}$ Huntington considered that core countries in the same civilization circle were the sources for the internal order within the region ${ }^{12}$, and they had the ability to work with the countries with similar cultures to reject the countries with different cultures ${ }^{13}$, and they also had the legitimacy to maintain and intensify orders and even to take the lead in the same civilization circle. ${ }^{14}$ This theory of Huntington, which was made from a perspective of long period and international area, well explained the facts of world sphere of influence and order for that time and present. However, when various factors are incorporated, the universal significance of core countries calls for investigation in various actual relations, rather than being generally valid.

In the history of East Asia, China was definitely a core country. ${ }^{15}$ No matter how macroscopic the theoretical framework of the tribute system is and how its discrepancy 
is in detail and specific relations, China as the core country is one of the keys for explaining the relations between the countries in this region-the negative evaluation upon the role of China in the history of East Asia, reversely, indicates at least there was such a fact. Undoubtedly, the core countries were bound to disappear in the history. Geological vicinity is not a condition for core countries, because the contemporary society changes rapidly, globalized communications become more and more close, and integration and communalization keeps expanding. Nowadays, East Asia is in the absence of core countries due to great differences in political systems and serious conflicts in ideology. Although China implements the socialist system, the Chinese government refuses universal values, constitutionalism and civil society, so that China cannot reach a consensus with Japan, Korea and other East Asian countries-though considerable consensus has been reached in liberal economy, free trade and other specific aspects. The role of core countries in a civilization circle, especially their legitimacy in establishing and maintaining orders, is stemmed from the common history on the premise of basic principles, and the similarity of some major factors in culture, social structure and concept structure, and so forth. Therefore, even though with the similarity of culture, social structure and concept structure, the role of core countries still cannot be played in the absence of the consensus in basic principles. East Asia's history in the past decades clearly demonstrates this point. Japan implemented liberal democratic systems after the Second World War and made great achievements in economy within a certain period to become the worlds' second largest economy, which boasted vital influences for the economy of East Asia. However, Japan never played the role of core countries in the history-though it tried to do so in modern times through colonization and aggression-hence there was no historical basis and legitimacy along with Japan's failure in assuming convincible moral obligations for the war and destruction; meanwhile, Japan always align with the US and becomes a member under the leadership of the US, so it lacks of the independent position. Therefore, Japan cannot become a core country.

No doubt, East Asia lacks of core countries-many facts support this point of view. Yet, the basic concepts and principles of core countries must be accepted by other countries. Here is the analysis by three levels and in time periods.

1) In the era of the so-called "tribute", or the era of one mighty China, the core values of Chinese society were generally accepted by the East Asian countries, especially North Korea and Japan who spontaneously introduced Confucianism and the other political concepts, though in different time periods. However, political system and social structure differed from each other to a large extent in many aspects.

2) At the beginning of the $20^{\text {th }}$ century, along with the overwhelming intervention of the Soviet Union, China was introduced with the Soviet socialist system and its universal values-communism. After the failure of the trial implementation in China for near 30 years, it came the policy changes of Chinese society. However, the earliest frustration was that the Soviet Union cannot incorporate China into its Socialist camp. Since the 1980s, Chinese society carried out the reform and opening-up policy, and the purpose for doing so was to gradually accept the universal values and principles of liberal economy and free trade. This policy, though difficult in implementation, made China break away from the closed system and go back to the world system, and of course, also return the civilization circle of East Asia-it is only a limited return as a matter of fact. 
No matter consciously or not, autonomously or passively, the economic system of China, as a whole, tended to execute the mainstream liberal economic principles of the contemporary world and establish corresponding optimal systems. After 15 years of strenuous efforts, the Chinese government made China access to the WTO. The purpose was to abide by the orders of liberal economy and free trade and share the benefits brought by the orders. The entry of China into the WTO is an indispensible condition for China to have comprehensive and in-depth economic cooperation and other kinds of cooperation with other countries in the world and also the only way for China to achieve huge economic progress. Nevertheless, the modern liberal economic system not is generally and basically a single economic system; it is also a political system, legal system and social system-namely, a compound system. Where political principles go against economic principles, the liberal economic system is bound to be incomplete and accompanied with a lot of vulnerabilities. For China, the separation of political principles and economic principles will result in that: internally, the power of liberal economy cannot be fully exerted, so did the potential of traditional Chinese spirits; externally, the contradictions and conflicts with the main countries which carry out liberal economic systems will be inevitably a continuous status, less alone participation in the operation and establishment of the world system in an active and effective way and endurance in the face of material risk and high cost.

In fact, in respects of the world order today and its composition and the basic principles, China still remains at a marginal position, which makes China beyond recovery of its position of core country. However, things are similar for other Easter Asian countries. In the absence of core countries, the East Asian countries, in facing of the alignment era of the modern world, are bound to take the countries of other regions as core countries (at least as core powers). The split-off of East Asia, meanwhile, means the constraints, conflicts, and consumption between the East Asian countries-or precisely speaking, the situation for their own business will sustain. Therefore, East Asia, as a whole, exists the lonely countries, such as China, Japan, Korea, North Korea, and Mongolia, as well as the lonely regions like Taiwan of China. Such an isolated condition only contributes to the mighty political, economic and other alliances of the powers outside of the region, no matter from what perspective.

3) Today, many Chinese people try to find out a concept system other than the classical core concepts of Marxism and liberalism, in a way to contend against the universal values such as liberty, democracy, constitutionalism and rule of law, or to at least replace them, However, they are confronted with the great difficulty: a concept system, no matter in which type or established in which form, should firstly resort to the free choice of the public and then conform to the principles of liberal economy ${ }^{16}$. Nowadays, quite a number of Chinese scholars try to fetch resources from Confucianism. It is no doubt an approach, yet is faced with the choice of the public. A historical phenomenon is reproduced no matter for Confucianism or resurgence of the "classics"-restoration of adjustability. After a tremendous revolution which wipes out traditional concept systems and social structures, it will take decades or even hundreds of years for the destroyed, prohibited and demolished basic social concepts, systems and structures to gradually recover-indeed, it is a renaissance of an updated pattern which features different degrees in restoration in 
different countries and times. The saying of Confucius (551 BC-479 BC) "renaissance of the annihilated empires, inheritance of the extinct noble families and promotion of the unattended talents" contains the same meaning, so that we can also understand from this perspective.

Here, one point should be noted that any opportunistic thoughts won't help form basic concepts and universal principles-if some concepts and principles apply to all Chinese people, they are impossible to fundamentally collide with the mainstream basic concepts of the world. Apart from the specific national identity, interpersonal relation, lifestyle and language, etc., their core factors should also apply to all other people. There are rather modern factors in Confucianism, especially in traditional Chinese political thoughts and systems-China is a precocious modern country in this sense, so that it inevitably has some appropriate modern factors, but the key is how to understand, study and judge the traditions of China. On the contrary, implementation of such factors as liberty, democracy and rule of law and embodiment of the principles and systems of these concepts will definitely reinforce Chinese people's national identity and even rational recognition; this kind of recognition is conductive to the consensus in basic principles between China and the East Asian countries.

Another viewpoint of Huntington is "international organizations": the international organizations established on the basis of the cultural commonality between different countries, such as the EU which is far more successful than other international organizations that attempt to surmount culture. ${ }^{17}$ In fact, classical examples in regard to Huntington's civilization circle and core country theories are precisely the Chinese civilization circle and the European alignment. The integration and communalization of East Asia is conceptually not only a design of modern people, as it also existed in the imagination of ancient people. For example, the "heaven" concept in Confucianism firstly contains East Asia, and of course, Vietnam. The so-called "tribute system" is just an embodiment of this concept. In this sense, this viewpoint of Huntington is not original with regard to the historical origin of concepts and political practices, but it are unique in the numerous and complicated contemporary international relations and world situations.

To further comprehend this viewpoint, we need to tell hostility from strangeness when we get to understand the East Asian relationship. Though there's no hostile emotion or mentality between the countries far from each other, they lack of the commonality in culture. In the history of the world, it was a common phenomenon for the countries and regions with common cultures to be hostile to and in warfare with each other-or arising from old resentments (including the differences in sphere of influence, territorial entitlement, religious faction and ideology), such as those between Athens and Sparta, the UK and France, Germany and France; or arising from the countries and regions with close relationship, such as West Germany and East Germany, Korea and North Korea, Mainland China and Taiwan. This kind of hostility (opposition or split-up) is out of complicated reasons and may behave in a fierce and brutal way, but it is easy to compromise once few fundamental factors are eliminated, such as the unification of West Germany and East Germany. Though this phenomenon is not explained in the paper, it is a key point for understanding the relationship between the East Asian countries. 


\section{Methods concerning the research of East Asia}

There are many influential theories for us to study the relationship between various political communities or countries in the history of the world, such as the "Toynbee Theory" which describes by civilization unit the history of the world and the rise and fall of civilizations, the "Wallerstein Theory" which explains the relationship between civilizations and countries by means of world systems, and the "Annales School" which studies civilizations and histories by combining society, economy and culture as a whole. Although these theories provide the patterns and theoretical means for understanding the past, now and future of East Asia, and are valid and quite instructive in a certain range, but they cannot completely address the real problem. Due to the dependence of historical theories upon historical reality, all these western theories cannot explain in a clearly and persuasive way the cause of formation of the self-contained East Asia in the world history and its fundamental relationship with the political communities or countries in the European history.

With regard to historical relationship, the East Asian countries underwent very few wars than the different European political communities and countries with frequent wards throughout history-such as the Sino-Japanese War which caused tremendous influence on the progress of social history and on the mentality of people, and the wars between China and North Korea in the history. The East Asian countries did not ever have religious wars, though the reasons for the conflicts between different countries varied from each other at various times in history. China, as a precocious modern country, established many mechanisms under the centralized bureaucratic system to deal with the various conflicts against the surrounding political communities or countries, in a way to avoid violence; while the "tribute system" provided other major means apart from warfare for solving conflicts in a long period.

The East Asian scholars made many studies for the "tribute system", which, as an ideal type or theoretical pattern, was firstly put forward by the US scholar John King Fairbank. Later, many responses and criticisms, including the contributions of the East Asian scholars, either modified this type or pointed out many of its vulnerabilities, yet no effective alternative pattern was put forward. This involves the methods of multiple levels: the primary and key point is that how to understand the phenomena that this ideal type aims at on the basis of historical facts; secondly, to try to comprehensively understand the correlation of various facts, one phenomenon can be and should be studied and explained in many perspectives. As for these two points, though the pattern of "tribute system" was put forward by modern people, the behaviors like "assembly", "alliance", "pilgrimage", "tribute" and "vassal" are existent in the Chinese civilization and its activity circle since ancient times. This historical fact and its influence on the relationship between China and East Asia and the international relationship as well can be studied from the perspectives of China or other countries; from the relationship between political communities or countries, or from the perspectives of politics, economy, military, concepts, diplomacy, etc. People may put forward other ideal types or patterns to understand and explain these phenomena and put emphasis on other levels. For instance, if it is the most economical choice for dealing with the relationship between political communities or countries under the restriction of various conditions in the ancient times. Besides, as for the systems and phenomena like "pilgrimage", "tribute" and "vassal", we need to clarify the relationship between the 
thoughts, actions, motivations and actual results of the people involved, their experience causality in historical transition, and the judgment and assessment of modern people, especially the viewpoints out of the western historical experience and modern people's experience-this is obviously not to deny its modern significance, while to well clarify its modern significance.

It is inevitable for people to judge and assess the behaviors of ancient people with modern concepts. However, acceptance or rejection of the historical events with the judgment and assessment of modern people will hinder people to get objective and appropriate knowledge, so that the judgers are required to have an open attitude. Indeed, even a serious historian cannot completely avoid the selection of the events involved for value judgment and the direction for narration, but objectivity and convinced reliability are still the principles and targets for academic research. This point is especially of necessary and realistic significance for understanding and cognition of the ancient and current relations of East Asia.

For example, the following commonalities can be usually found in the chapters narrating the relations between countries in the historical works of the East Asia countries: (1) take western calendar and history as the reference systems; what's more, simply adopt the theories of western ideology; (2) emphasize the suffering of their own countries or the countries with inheritance relationship, i.e., their history of invasion and colonization, etc., while avoiding the facts of invasion or warfare by their own countries or motherlands towards other countries, or just understating the facts; (3) emphasize and criticize foreign invasions, while proud of the territory expansion of their own nations or countries, which is harmful because they avoid and ignore historical events on the excuse of the difficulties in conforming to the modern international standards and meeting the realistic national interests in the actual historical writing; (4) avoid the conflicts in the history for the current national relations, so as not to hinder correct and objective cognition for the history, which is harmful for understanding and positioning the realistic national relations. The realistic national relations are formed by various factors in the history and the multiple actions of modern people, so that they are not caused and restricted by a certain factor.

Beyond doubt, the significance of methods is multiple here: the history of the East Asian countries and their realistic social structures, economic forms, political systems, social mentalities and mutual relations are studied from different perspectives and levels, while various different contexts and clues are clarified, in a way to determine in what aspects the East Asian countries can never obtain overlapping consensus, and in what aspects they can find out this consensus or at least reach overlapping or crossed consensus in some parts or aspects, hence forming a level of consensus.

Apart from theoretical pattern and historical explanation, as for human behavior and the state behavior based thereupon, methods are of the significance as follows both in theory and practice: exchanges and cooperation come first than consensus. In other words, more common points will be reached though exchanges and cooperation, eliminating those differences that can be eliminated, including but not limited to the differences that can cause obstacles in respects of politics, laws, society, mentality, etc. In fact, people definitely act in this way. From this point of view, it is valid for such a principle that: actions always come first than theories. Hence, the willpower and determination for putting things into practice come first. In the evolution of human society, 
actions always come first than the plans and assumptions with some certainty in establishing the various relations of mankind, and there are no absolutely safe plans. Therefore, all the validity of theories and methods is based on such action determination. In this sense, the willpower and determination for putting things into practice are the element methods for establishing the various relations of mankind. This is the reason for why economic cooperation and personnel exchanges are basic and most feasible approaches for the future of East Asia. There are also contradictions and conflicts in this field and process, but they are more realistic actions that benefit people by comparison with political exchanges, and always the actions spontaneously in process, so that they can easily break through conflicts and obstacles. ${ }^{18}$

The real alliance of East Asia start from economic and personnel exchanges and cultural, political and legal exchanges and cooperation, through the unavoidable approaches of politics and legality, finally to the form of integration and communalization. Only this form is the positive prospect for the future of East Asia. When we discuss the research and thinking methods concerning East Asia's history and future on this basis, we need to pay particular attention to the following two points which are seemingly opposite yet actually supportive to each other: common concepts and principles and their particularity: when consensus is reached to the maximum extent, maintenance of social and culture particularity between different countries is the only way out. Consensus is finally reflected in politics, and then in legality, while society and other levels like culture always keep the nature of non-politics, retaining the free space between laws.

It concerns the explanation theories for the differences between contemporary countries and even races. There are great differences in economics, society, culture development and other aspects for different countries even in the EU. Under the common basic concepts and liberal democratic systems of the EU countries, and under the common political, legal and economic frameworks and principles of the EU, how to understand the existence and continuance of these differences? This needs to be explained from the level of social behaviors of individuals-concept structures. Under the common political concepts and systems, and even under the common legal systems, social concept structures, behavior modes and lifestyles of the people of different races are different, while the unique social behaviors-concept structures of each race will not only sustain for a long time, but also keep developing. People's economic behaviors and lifestyles, to a large extent, are dominated and affected by such a dual structure. Of course, social behaviors-concept structures will change, but the process is rather slow. Even if they are involved in huge social transitions like revolution, they can still substantially recover in the new political system and other systems and environments; however, such a structure contains multiple correlated factors, so that they will recover in different directions, or different factors will be amplified, while some factors will be restrained. For instance, the differences between the current economic conditions of Germany and that of the other countries of the EU should be studied and explained from the level of social behaviors-concept structures. Otherwise, such differences and discrepancies will always be inexplicable. ${ }^{19}$

This consciousness of methodology is very helpful for us to understand and cognize the cooperation of East Asia and its probable integration and communalization. Although China, Japan, Korea and other countries have great differences in political 
systems and ideology, they still enjoy something quite common in social behaviors-concept structures. Hence, one preliminary conclusion can be drawn: the seemingly huge political and ideological differences and the obstacles brought in thereof could be rather superficial in fact, so that they can be easily changed; however, the social behaviors-concepts infiltrated in people's daily lifestyles seem not so important, but they are critical factors in the long-term evolution of society, and even play a decisive role. We have to say that this is a fundamental point for us to understand the cooperation, transition and prospects of East Asia, and for our confidence in the future integration and communalization of East Asia as well.

\section{Endnotes}

${ }^{1}$ Guo D. (ed), Theory and Practice on Building the East Asian Community, Shanghai: Fudan University Press, 2008, p7 (Guo 2008).

2"24-Nation Pew Global Attitudes Survey", Pew Global Attitudes Project (Pew Research Center, 2008), 35 (http://www.pewresearch.org) ("24-Nation Pew Global Attitudes Survey" 2008).

${ }^{3}$ The mentality herein mainly refers to people's mental conditions, attitudes and opinions.

${ }^{4}$ Sun, Y-s, Sun Yat-sen Quanji, vol. 11, Beijing: Zhonghua Book Company, 1986, p409 (Sun 1986).

${ }^{5}$ Benedetto Croce (translated by Douglas Ainisilie), History Its Theory and Practice, New York: Harcourt, Brace and Company, 1923, p13 (Croce 1923).

${ }^{6}$ Jasper, Karl, (edit.by John Dreijmanis) Karl Jaspers On Max Weber, New York: Paragon House, 1989, pp170-171 (Jasper 1989).

${ }^{7} 96 \%, 76 \%$ and $41 \%$ of people respectively in Korea, China and Japan think that the apology is not enough, while $42 \%$ of Japanese people think that the apology is enough. "24-Nation Pew Global Attitudes Survey", Pew Global Attitudes Project (Pew Research Center, 2008), p35, (http://www.pewresearch.org/files/pdf/260.pdf)

${ }^{8}$ During the separatist war of Yugoslavia, the EU countries selectively supported the race expelling and cleaning of certain clans, while suppressed the race expelling and cleaning of other clans.

${ }^{9}$ Kant said something significant: "Just as nature wisely separates states that the will of each state, and even on grounds of the right of nations, would like to unite under itself by cunning or force, so on the other hand it also unites nations that the concept of cosmopolitan right would not have secured against violence and war, and does so by means of their mutual self-interest. It is the spirit of commerce, which cannot coexist with war and which sooner or later takes hold of every nation." Immanuel Kant, Kants Werke, Akademie Textausgabe VIII, Abhandlungen nach 1781, Berlin: Walter de Gruyter, 1968, Seite 336.

${ }^{10}$ Immanuel Kant, Kants Werke, Akademie Textausgabe VIII Abhandlungen nach 1781, Berlin: Walter de Gruyter, 1968, Seite 382 (Immanuel Kant 1968).

${ }^{11}$ Huntington, S. P., The clash of civilizations and the remaking of world order, New York City: Simon \& Shuster Publisher, 2007, p135 (Huntington 2007).

${ }^{12}$ Huntington, S. P., The clash of civilizations and the remaking of world order, New York City: Simon \& Shuster Publisher, 2007, p156. 
${ }^{13}$ Huntington, S.P., The clash of civilizations and the remaking of world order, New York City: Simon \& Shuster Publisher, 2007, p155.

${ }^{14}$ Huntington, S.P., The clash of civilizations and the remaking of world order, New York City: Simon \& Shuster Publisher, 2007, p156.

${ }^{15}$ China as the core country is the main historical and realistic basis for The Clash of Civilizations and the Remaking of World Order of Huntington and the main basis for his argument. Refer to Page 167, Page 181 and the pages thereafter of the book.

${ }^{16}$ Political report of the 18th CPC National Congress suggested the core values of "prosperity, democracy, civilization, harmony, liberty, equality, justice, rule of law, patriotism, devotion, honesty, and friendship". The items such as liberty, democracy, equality and rule of law are actually basic concepts except for the items of high moral requirements and logical repetitions. They are acknowledged by the constitutions of almost all countries. Moreover, China is the earliest in accepting these concepts from a constitutional level in Asia.

${ }^{17}$ S. P. Huntington: The Clash of Civilizations and the Remaking of World Order, P7.

${ }^{18}$ For example, the Sino-Japanese relations became strained due to the Diaoyu Islands dispute, but the number of the Chinese visitors to Japan in 2014 was nearly 2 million, which reached a record high (Huanqiu Net, 2014-09-25). Besides, 65\% of the Chinese students studying in Japan were employed in Japan in 2014 ("Xinhua Net", 2014-09-16).

${ }^{19}$ This kind of basic political concepts different from countries or political communities, and the social behaviors-concept structures of basic political, legal and economic systems are not further described herein, while they are specially described in anther paper.

\section{Competing interests}

I declare that I have no significant competing financial, professional or personal interests that might have influenced the performance or presentation of the work described in this manuscript.

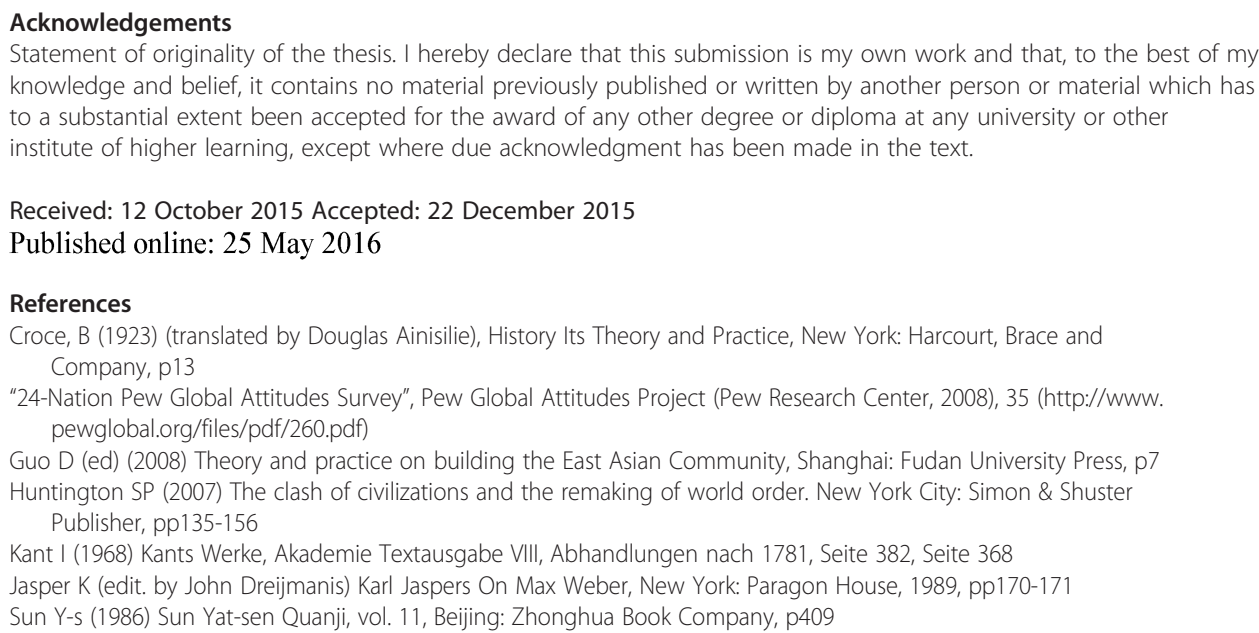

